Research Paper:

\title{
Comparing the Effects of Creativity Therapy and Group Counseling Based on Choice Theory on Students' Exile Feeling and Thought Emotion
}

\author{
Fahime Yoosefi Jooybari ${ }^{1}$ (D), Ramazan Hassanzadeh ${ }^{1^{*}}$ (D), Mohammad Kazem Fakhri ${ }^{1}$ (C)
}

1. Department of Psychology, Sari Branch, Islamic Azad University, Sari, Iran.

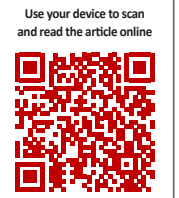

ditation Yoosefi Jooybari F, Hassanzadeh R, Fakhri MK. Comparing the Effects of Creativity Therapy and Group Counseling Based on Choice Theory on Students' Exile Feeling and Thought Emotion. Avicenna J of Neuropsychophysiology. 2017; 4(2):71-78. http://dx.doi.org/10.32598/ajnpp.4.2.71

doif': http://dx.doi.org/10.32598/ajnpp.4.2.71

Funding: See Page 77

(c) Copyright: The Author(s)

Article info:

Received: 27 October 2017

Accepted: 20 February 2017

Available Online: 01 May 2017

Keywords:

Creativity therapy, Choice theory, Nostalgia, Thought emotion

\begin{abstract}
Introduction: Nostalgia is described as a stressful reaction to being away from home or attachment objection (like parents). According to the thought emotion theory, affection and cognition are very important in creativity process.
\end{abstract}

Objectives: The present study compares the effectiveness of creativity therapy and group counseling based on the choice theory on the nostalgia and thought emotion of university students.

Materials and Methods: The participants of this study included all students referring to the counseling center of Payame Noor University, Sari Center, in 2016-2017 academic year. The convenience sampling method was used for the selection of the subjects. The sample consisted of 45 individuals who were randomly divided into two experimental and one control group ( $\mathrm{n}=15$ in each group). In pretest, the exile feeling and thought emotion questionnaires were administered to all groups. One experimental group received the creativity therapy and the other group counseling training based on the theory of choice in eight 90-minute sessions for 2 months. The control group did not receive training during this period. After completing the training, posttest was obtained from three groups. The obtained data were analyzed using covariance analysis in SPSS V. 16.

Results: The results showed a significant difference between the effectiveness of creativity therapy training and group counseling based on choice theory in relieving students' nostalgia and thought emotion $(\mathrm{P}<0.05)$. Also, the experimental interventions (group training based on group choice theory and creativity therapy) decreased the nostalgia and reduced thought raptus and increased thought dynamism in students.

Conclusion: Creativity therapy training and group counseling based on choice theory may be effective in improving nostalgia and thought emotion in students.

\section{* Corresponding Author:}




\section{Introduction}

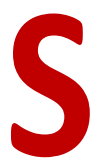

tudents who immigrate to other cities or countries to continue their educations may encounter with mental symptoms such as nostalgia and depression. Nostalgia is described as a stressful reaction to being away from home or attachment objection (parents) [1]. The most important signs of nostalgia are depression, anguish of not supporting by others, anxiety, tedium, and avoiding people [2, 3]. Some strategies and therapies against nostalgia include being away from home exercise, confronting strategies, having many friends and so on $[2,4]$.

Today, concepts of Glasser's choice theory are very important in educational psychology. Emphasis upon feeling of responsibility is known as an effective factor in decreasing nostalgia [5]. Reality-therapy is based on control theory and assumes that people are responsible for their actions, behaviors and feelings [6]. According to choice theory, we do not satisfy our needs directly. Postural world is described one brain part that we store some actions which result in good feeling. Humans are the most important element of our postural world [7]. According to choice theory, we need to love and be loved because we are social beings [8].

According to Glasser (2001), love demand is a basic need and we need people to satisfy other's needs. However, satisfying this need is very difficult because we need to a person who satisfies it [6]. Humans get agitated by basic needs and control environment to satisfy their needs [6]. Creativity therapy is a new therapy for psychological health [9]. Creativity is the ability to create compatible opinions. A creative person seeks new solutions that may result in more challenge so he or she need high self-confidence [10]. The psyche health model based on creativity believes that human has high capacity to improve himself or herself. In fact, improving internal abilities may result in psyche health [11]. According to Pirkhaefi (2014) study, high creativity may lead to lower depression and anxiety, better adjustment, more flexibility and optimism, more positive affections and effective adaptive skills [10]. All of these factors could decrease nostalgia because depression and anxiety are among nostalgia consequences. Moreover, adaptive skills, extended positive affections and optimism are therapeutic strategies to remedy nostalgia $[2,4]$.

Based on thought emotion theory, affection and cognition are very important in creativity. Thought emotion consists of dynamism and raptus components [12].
Dynamism is high force feeling to have one big exciting exploration and raptus refers to fear and agitation of thought. It shows itself in the form of physical signs and person feels high pressure in his/her activity [13]. According to studies, low anxiety and high mental health are necessary to have creativity [13].

Emotional agitation is one preventive factor against creativity. Understanding relationship between cognitive action and affective field is important to improve critical thinking. Therefore, coordination between thought and emotion is important for creativity. Some researchers emphasize on more than antonym feature ten couples among creative persons [13]. Avrill et al. (1996) claimed that high creativity may result in better expression of emotions. They concluded that creative people may combine antithetical emotions and find a creative solution for unsolved conflicts [14]. Seligman believes that creativity may improve internal capacities [14]. They believed that creativity may activate internalized positive capacities [11].

Therefore, creativity therapy may be effective on thought emotion and nostalgia. Also, according to Glasser's choice theory, teaching these components is effective upon person's emotions [15]. Literature review revealed that no coherent studies have been conducted about different therapies upon this topic. This study aimed to compare the effectiveness of creativity therapy and group counseling based on choice theory upon nostalgia and thought emotion among university students.

\section{Materials and Methods}

The present research is a quasi-experimental study with pretest posttest and control group. The study population included all students referring to the counseling center of Payame Noor University, Sari Center, in 20162017 academic year. The convenience sampling method was used for the selection of the subjects. The sample consisted of 45 individuals who were randomly divided into two experimental and one control group (15 individuals per group).

The inclusion criteria were studying at Sari Payame Noor University, having physical and mental ability to participate in the research, informed consent to participate in research and exclusion criteria included refusing to answer questionnaire items or leaving the study for any reason. Because the research has conducted in one term in 2016-2017, answering to questionnaire and posttest questions and continuous participating at ses- 
sions resulted in decreasing the number of participants. First, all students referring to the counseling center were identified and then necessary explanations about the research and confidentiality of the obtained information were provided.

Then the students were entered the study after obtaining their informed consent. In pretest, exile feeling and thought emotion questionnaires were administered to all study groups. The experimental group received the training of group therapy and group counseling based on the theory of choice in eight 90-minute sessions for 2 months. The control group did not receive training during this period. After completing the training, posttest was administered to three groups. The obtained data were analyzed using covariance analysis in SPSS V. 16. The current research was approved by Ethics Committee of Islamic Azad University Sari Branch.

\section{Study tools}

\section{Nostalgia Questionnaire}

The nostalgia standard questionnaire includes 36 items and 5 components of "tedium for family", "returning tendency to country", "feeling of loneliness", "maladjustment with new environments", and "tedium for intimate friends". Scoring of this questionnaire is based on 5-point Likert scale (never $=1$; little $=2$; average $=3$; much $=4$; very much $=5$ ). The lowest score is 36 and the highest is 181 . Higher score indicates more severe nostalgia feeling. Ejei and colleagues (2008) checked questionnaire reliability by calculating the Cronbach's $\alpha$ value for "tedium for family", "returning tendency to country", "maladjustment", "feeling loneliness" and "tedium for familiar persons and environment" as 0.90, $0.89,0.85,0.84$, and 0.69 , respectively [16]. Moreover, the Cronbach's $\alpha$ value for nostalgia total score was 0.86 in the present study.

\section{Thought Emotion Questionnaire}

The 12-factor "thought emotion" includes 69 questions and has two scales of "dynamism" and "raptus" and each assesses 6 factors. Product-moment correlation coefficient was between 0.39 and 0.74 for dynamism scale and between 0.40 and 0.75 for raptus scale; both were significant. Correlation coefficients were 0.13 for the two scales, 0.76 for raptus scale and test, and 0.67 for dynamism scale and test. Validity coefficients of "dynamism scale" "raptus scale" and whole test were $0.90,0.92$ and 0.89 , respectively.

"Dynamism scale" includes movement, curiosity, severe powerfulness feeling, big exploring, emotion displaying, and experimental infatuation and "raptus scale" includes agitation, internal capacity, thought displaying, fear, thought ambulation and being under pressure feeling for activity [13]. It should be noted that thought emotion scale reliability for raptus and dynamism and whole scale were calculated by Cronbach's $\alpha$, which were $0.72,0.76$ and 0.74 , respectively.

\section{Therapy sessions}

Therapy sessions are presented in Tables 1 and 2 .

Table 1. Group counseling based on choice theory training sessions

\begin{tabular}{|c|c|}
\hline Session & Session Subject \\
\hline Session 1 & $\begin{array}{c}\text { Group members become familiar with each other, introducing group counseling principles, explaining about choice } \\
\text { theory concepts, introducing basic needs to subjects, becoming familiar with needs rate extremity and drawing } \\
\text { needs profile }\end{array}$ \\
\hline Session 2 & $\begin{array}{l}\text { Identifying difference rate of students' needs profile, becoming familiar with behavior car (thought, action, feeling } \\
\text { and physiology) and more cognition each member from himself/herself }\end{array}$ \\
\hline Session 3 & Becoming familiar with reality therapy concept and creating responsibility feeling to satisfy basic needs \\
\hline Session 4 & $\begin{array}{l}\text { Instruction of reality therapy techniques, becoming familiar with external control concept and its destructive role in } \\
\text { hearty relationships and replacing of internal control instead external control }\end{array}$ \\
\hline Session 5 & $\begin{array}{l}\text { Becoming familiar with the talk over way about uncoordinated needs, cognition of aims and values and cognition of } \\
\text { basic needs (physiological need, authority need, amusement need, freedom need), attachment feeling and identity }\end{array}$ \\
\hline Session 6 & $\begin{array}{l}\text { Instruction of quality world concept, stating the importance of student's satisfaction from it and the way of planning } \\
\text { for problem-solving based on present time. }\end{array}$ \\
\hline Session 7 & $\begin{array}{l}\text { Becoming familiar with conflict concept and conflict relation with quality world and basic needs and instruction of } \\
\text { some techniques to increase happiness }\end{array}$ \\
\hline Session 8 & Receiving feedback from previous sessions \\
\hline
\end{tabular}


Table 2. Creativity therapy training sessions

\begin{tabular}{|c|c|c|}
\hline Session & Subject & Aim \\
\hline Session 1 & Introduction of communicating & $\begin{array}{c}\text { Introducing, becoming familiar with instructor, learning concept, kinds } \\
\text { of memory and its structure, amnesia reasons, stating clinical model of } \\
\text { creativity therapy, distributions and aims }\end{array}$ \\
\hline Session 2 & $\begin{array}{l}\text { Instruction of creating metacognitive } \\
\text { components }\end{array}$ & $\begin{array}{l}\text { Fluency and flexibility were instructed from metacognitive component. } \\
\text { We want that persons may use mental dynamism to change at quantity, } \\
\text { diversity and novelty of mental products level. }\end{array}$ \\
\hline Session 3 & $\begin{array}{l}\text { Instruction of creating metacognitive } \\
\text { components }\end{array}$ & $\begin{array}{l}\text { Instruction of second step (mental design, thought reforming, understand- } \\
\text { ing and problem-solving) }\end{array}$ \\
\hline Session 4 & $\begin{array}{l}\text { Instruction of creativity metacogni- } \\
\text { tive components }\end{array}$ & Instructing the third step (making decision) \\
\hline Session 5 & Language components of creativity & $\begin{array}{l}\text { Language components of creativity therapy (reforming and word perceptu- } \\
\text { al expanding, semantic extending and verbal relationships) were introduced }\end{array}$ \\
\hline Session 6 & Motivational components & $\begin{array}{l}\text { Creativity therapy, motivational components including motivational orien- } \\
\text { tation and assiduity }\end{array}$ \\
\hline Session 7 & Personality components & $\begin{array}{c}\text { Creativity therapy, personality components including self-confidence, } \\
\text { adventure and risk }\end{array}$ \\
\hline Session 8 & Body language components & $\begin{array}{l}\text { Creativity therapy body language components including motor behaviors } \\
\text { and body language }\end{array}$ \\
\hline
\end{tabular}

AJNPP

\section{Results}

According to Table 3, most samples aged between 26 and 30 years and the age range of 36- 40 years $(13.34 \%)$ had the least frequency. About $57.78 \%$ and $42.22 \%$ of the subjects were females and males, respectively. Table 3 shows the sampling distribution based on age and gender.

The mean and standard deviation of the participant's scores in thought emotion and nostalgia questionnaires for study groups are presented in Table 4. Apparently, the mean (SD) nostalgia score for the experimental group of creativity therapy, experimental group of counseling therapy based on choice theory, and control group at pretest stage were 129.066(11.64), 133.80(15.55) and 135.33(15.55), respectively. Their values at posttest for the mentioned groups were 93.40(4.64), 70.40(9.75) and $134.40(14.17)$, respectively. The other related results are presented in Table 4.

It is necessary to consider the most important presumptions including data normality. According to the results, the distribution of nostalgia, thought raptus and thought dynamism are normal $(P<0.05)$. The other presumption was variances equality which was calculated more than 0.05 for all dimensions $(P<0.05)$. The other

Table 3. Frequency distribution and percentage of sample based on age and gender

\begin{tabular}{cccc}
\hline Variable & Range & No. & $\%$ \\
\hline & $20-25$ & 13 & 28.89 \\
Age, y & $26-30$ & 15 & 33.33 \\
& $31-35$ & 11 & 24.94 \\
& $36-40$ & 6 & 13.34 \\
Gender & Female & 26 & 57.78 \\
& Male & 19 & 42.22 \\
\hline
\end{tabular}


Table 4. Thought emotion and nostalgia questionnaires mean (SD) scores for study groups at pretest and posttest

\begin{tabular}{|c|c|c|c|c|c|c|c|}
\hline \multirow{3}{*}{ Questionnaires } & \multirow{3}{*}{ Test } & \multicolumn{4}{|c|}{ Experimental Group } & \multirow{2}{*}{\multicolumn{2}{|c|}{ Control Group }} \\
\hline & & \multicolumn{2}{|c|}{ Creativity Therapy } & \multicolumn{2}{|c|}{$\begin{array}{l}\text { Group Counseling Therapy } \\
\text { Based on Choice Theory }\end{array}$} & & \\
\hline & & Mean & SD & Mean & SD & Mean & SD \\
\hline \multirow{3}{*}{ Nostalgia } & Pretest & 129.06 & 11.64 & 133.80 & 15.55 & 135.33 & 15.55 \\
\hline & & & & & & & \\
\hline & Posttest & 93.40 & 4.64 & 70.40 & 9.75 & 134.40 & 14.17 \\
\hline \multirow{2}{*}{ Thought raptus } & Pretest & 79.73 & 10.09 & 84.13 & 9.10 & 75.93 & 9.63 \\
\hline & Posttest & 43.13 & 5.13 & 51.066 & 12.35 & 72.33 & 11.43 \\
\hline \multirow{2}{*}{ Thought dynamism } & Pretest & 55.46 & 11.47 & 59.53 & 11.40 & 66.40 & 11.62 \\
\hline & Posttest & 96.33 & 11.93 & 79.86 & 10.76 & 66 & 12.24 \\
\hline
\end{tabular}

Table 5. Differences of two experimental groups tested by multivariate covariance analysis test

\begin{tabular}{ccccccc}
\hline Statistical Index & Value & F & df & Error, df & Eta Coefficient & 0.79 \\
\hline Pillai's Trace & 0.798 & 30.26 & 3 & 23 & 0.01 \\
Wilks Lambda & 0.202 & 30.26 & 3 & 23 & 0.79 \\
Hotelling Trace & 3.94 & 30.26 & 3 & 23 & 0.79 \\
Roy's Largest Root & 3.94 & 30.26 & 3 & 23 & 0.79 \\
\hline
\end{tabular}

AJNPP

presumption i.e., variance-covariance matrix consistency was confirmed by the M-BOX test.

The differences of two experimental groups tested by multivariate covariance analysis are presented in Table 5. As can be seen, there is a significant difference between two groups regarding the nostalgia, thought dynamism and thought raptus $(P<0.001)$. As can be seen in Table 6, there is a significant difference between two experimental groups regarding the nostalgia $(P<0.001)$, thought dynamism $(P<0.002)$ and thought raptus $(P<0.014)$. In other words, the effectiveness of creativity therapy and group counseling based on choice theory upon nostalgia, thought dynamism and thought raptus are significant.

Based on the Bonferroni method, there is a significant difference between thought dynamism $(P<0.001)$

Table 6. Multivariate covariance analysis of nostalgia, thought dynamism, and thought raptus at posttest

\begin{tabular}{|c|c|c|c|c|c|c|c|}
\hline Source & Subscales & Sum of Squares & df & Mean Square & $\mathbf{F}$ & Sig. & Eta Value \\
\hline \multirow{3}{*}{ Pretest } & Nostalgia & 0.190 & 1 & 0.190 & 0.004 & 0.952 & 0.001 \\
\hline & Thought dynamism & 113.53 & 1 & 113.53 & 2.18 & 0.152 & 0.08 \\
\hline & Thought raptus & 308.95 & 1 & 308.95 & 5.93 & 0.022 & 0.192 \\
\hline \multirow{3}{*}{$\begin{array}{c}\text { Group } \\
\text { membership }\end{array}$} & Nostalgia & 3182.61 & 1 & 31282.61 & 61.11 & 0.001 & 0.71 \\
\hline & Thought dynamism & 1492.58 & 1 & 1492.58 & 12.29 & 0.002 & 0.330 \\
\hline & Thought raptus & 580.36 & 1 & 580.36 & 6.98 & 0.014 & 0.218 \\
\hline
\end{tabular}


and nostalgia $(P<0.001)$. Creativity therapy effect on thought dynamism score increase was more effective than group counseling therapy, also group counseling therapy effect upon nostalgia score decrease was more effective than creativity therapy. There was no significant difference between two group's scores with regard to thought raptus score $(P<0.05)$. The univariate covariance analysis test showed that creativity therapy decreased nostalgia score at posttest stage $(P<0.001)$.

Also, the multivariate covariance analysis test showed that the difference between experimental group (creativity therapy) and control group with regard to thought dynamism and thought raptus was significant $(\mathrm{P}<0.001)$. Therefore, creativity therapy has led to an increase in thought dynamism score and decrease in thought raptus score $(P<0.001)$. Univariate covariance analysis showed that group counseling based on choice theory has resulted in a decrease in nostalgia score $(P<0.001)$. According to the multivariate covariance analysis, the difference between experimental group (group counseling based on choice theory) and control group upon thought dynamism and thought raptus is significant $(P<0.001)$. Indeed, the group counseling based on choice theory has resulted in an increase and decrease in thought dynamism score and thought raptus, respectively.

\section{Discussion}

The present research aimed to study the effectiveness of creativity therapy and group counseling base on choice theory upon nostalgia and thought emotion among the students. The results are congruent with Mumford 2012 [17] and Pirkhaefi 2009 research [11]. It was found that creativity therapy upon increase in thought dynamism was more effective than group counseling therapy according to choice theory. Based on Pirkhaefi's research (2009), creativity training increases creativity metacognitive components level in instructed students [11]. Regulated creativity instruction may improve metacognitive components [11].

The difference of creativity therapy with other therapeutic models is that it considers a suitable place for creativity as a sole factor managing internal changes [18]. Creativity is both an ability and a meta-ability, i.e., it reinforces other abilities and mental and personal capacities [12]. Creativity therapy emphasizes upon internal creativity (mind and personality) to attain normal behaviors [19]. Age range is important to execute this technique; first, persons must be identified about their creative capacities, then they should be aware of appraisal and finally exercise facilities will be provided [19].

The creativity therapy model (two-dimensional model) consists of self-efficacy and creative adaptation elements that are active at 5 levels of metacognition, language, motivation, personality, and movement. And the result is improving mind and personality toward health and constructivity [12]. The Pirkhaefi (2009) model, which describes psyche health based on creativity, states that human has enormous ability to improve; therefore, personal abilities and capacities are more important than person's weaknesses. In fact, improving internal abilities may result in psyche health [11].

According to different studies, creativity instruction may result in flexibility, imagination and mental ingenuity, mental well-being and adaptive procedures efficacy (question-focused or emotion-focused coping). Boosting these qualities may improve psyche health $[20,21]$. Therefore, training these features of creativity therapy may decrease nostalgia in students. According to our results, group counseling therapy effect (based on choice theory) on decreasing nostalgia score was more effective than creativity therapy.

Glasser's choice theory is based on control psychology because humans have the ability to choose with respect to their personal and professional behaviors. Reality therapy helps people to manage and control their plans. Control theory is the main concept of reality therapy and is one of basic principles to prevent negative emotions such as person's nostalgia. Studying various research studies about positive effect of creativity therapy upon thought dynamism score increasing showed that they have several effective mental and personal models. These models include new analysis and mind, mental and behavioral flexibility, adventure mentality, high selfconfidence, and high assiduity that all of them may be the features of creative people [22, 23].

McDonnell (2014) reported a positive relationship between creativity and psyche health [24]. According to thought emotion theory, affection and cognition are very important in creativity process. However, creativity does not affect flexibility and students expansion but on ingenuity and fluidity. Sex variable also may be a source of incongruence. Cultural difference and bilingualism are the other effective factors, too. Creativity is a process that leads to new thoughts. Students need too much information to challenge old thoughts, emotions and opinions. Thought emotion consists of dynamism and raptus components [12]. Dynamism is high force 
feeling to have one big exciting exploration and raptus refers to fear and agitation of thought. It shows itself in the form of physical signs so that the person feels high pressure in his/her activity [13].

Shafieeabadi and Gholamhossein in their research found that endurance skills training in group was effective upon mental and emotional health of students. It resulted in stress relief and communication improvement [25]. Other results indicate that group counseling based on choice theory increases thought dynamism score and decreases thought raptus. One of the main components of thought dynamism in thought emotion theory is psychological tenacity, including control, commitment and challenge components [26-28]. Reality therapy is based on control [29].

Some questions may be presented by reality therapist to identify client desires; These questions are categorized as: 1. Identification of desires: what are client desires and perceptions? 2. Process identification: what does client do in the fields of doing, thinking, and feeling? 3. Self-appraisal: how does client do some actions related to his/her desires? 4. Self-control displays: how can a person change his/her behavior? and 5. Planning: how should one plan for change? [27]. The main element of choice theory indicates that learner chooses, regulates, and controls his or her environment. Obviously, some contents of educational programs based on Glasser's choice theory are similar to thought emotion theory concepts. For this reason, training of this theory has a significant effect on thought emotion.

\section{Conclusion}

The results showed a significant difference between the effectiveness of creativity therapy and the group counseling (based on choice theory) on nostalgia and thought emotion compared to the control group. In fact, the experimental interventions (group training based on group choice theory and creativity therapy) resulted in a decrease in both nostalgia score and thought raptus and accordingly an increase in thought dynamism among the students. Therefore, creativity therapy training and group counseling based on choice theory may improve nostalgia and thought emotion among the students.

\section{Ethical Considerations}

\section{Compliance with ethical guidelines}

All the participants were given information about the goal of the study. They were aware that taking part in this study was voluntary and had the right to refuse participation or leave the study whenever they wish.

\section{Funding}

This article is part of a PhD thesis in Islamic Azad University, Sari Branch. This research did not receive any specific grant from funding agencies in the public, commercial, or not-for-profit sectors

\section{Conflict of interest}

The authors have no conflict of interest to declare.

\section{Acknowledgements}

It is necessary to appreciate all persons who assisted us in this research, especially the study students.

\section{References}

[1] Thurber CA, Walton EA. Preventing and treating homesickness. Pediatrics. 2007; 119(1):192-201. [DOI:10.1542/ peds.2006-2781] [PMID]

[2] Sun J, Hagedorn LS. Homesickness at college: Its impact on academic performance and retention. Journal of College Student Development. 2016; 57(8):943-57. [DOI:10.1353/ csd.2016.0092]

[3] Stroebe M, Schut H, Nauta M. Homesickness: A systematic review of the scientific literature. Review of General Psychology. 2015; 19(2):157-171. [DOI:10.1037/gpr0000037]

[4] Thurber CA. Multimodal homesickness prevention in boys spending 2 weeks at a residential summer camp. Journal of Consulting and Clinical Psychology. 2005; 73(3):555-60. [DOI:10.1037/0022-006X.73.3.555]

[5] Gardner S. Choice theory: Gender roles and identity. International Journal of Choice Theory and Reality Therapy. 2015; 35(1):31-9.

[6] Glasser W. Counseling with choice theory: The new reality therapy. New York: Harper Collins; 2001.

[7] Seligman MEP, Csikszentmihalyi M. Positive psychology: An introduction. In: Csikszentmihalyi M, editor. Flow and the Foundations of Positive Psychology. Dordrecht: Springer; 2014. [DOI:10.1007/978-94-017-9088-8_18]

[8] Halasz G. Special population-child and adolescent psychotherapy. Australasian Psychiatry. 2017; 25(3):222-4. [DOI:10.1177/1039856216689622]

[9] Scott G, Leritz LE, Mumford MD. The effectiveness of creativity training: A quantitative review. Creativity Research Journal. 2004; 16(4):361-88. [DOI:10.1080/10400410409534549] 
[10] Pirkhaefi A. [A Treatise on therapeutic creativity: An evolutionary approach to mental Health (Persian)]. Tehran: Mehraban Publication; 2014.

[11] Pirkhaefi A. [The effect of creativity training on meta-cognitive components of student's thinking (Persian)]. Quarterly Journal of Educational Leadership \& Administration. 2009; 3(2):51-61.

[12] Mascia D, Magnusson M, Björk J. The role of social networks in organizing ideation, creativity and innovation: An introduction. Creativity and Innovation Management. 2015; 24(1):102-8. [DOI:10.1111/caim.12111]

[13] Navabakhsh M, Kazemi Haghighi N. Social consideration in the creativity: Resource orientation. International Journal of Social Sciences. 2011; 1(1):57-66.

[14] Averill JR. Creativity in the domain of emotion. In: Dalgleish T, Power MJ, editors. Handbook of Cognition and Emotion. New Jersey: John Wiley \& Sons; 1999. [DOI:10.1002/0470013494.ch36]

[15] Toyama H, Mauno S. Associations of trait emotional intelligence with social support, work engagement, and creativity in Japanese eldercare nurses. Japanese Psychological Research. 2017; 59(1):14-25. [DOI:10.1111/jpr.12139]

[16] Ejei J, Dehghani M, Ganjavi A, Khodapanahi MK. [Validation of Utrecht Homesickness Scale in students (Persian)] International Journal of Behavioral Sciences. 2008; 2(1):1-12.

[17] Mumford MD, Medeiros KE, Partlow PJ. Creative thinking: Processes, strategies, and knowledge. The Journal of Creative behaviour. 2012; 46(1):30-47. [DOI:10.1002/jocb.003]

[18] Turner M. Creative therapy in the treatment of trauma in adolescents [PhD dissertation]. San Diego: Alliant International University; 2016

[19] Mirzazadeh M, Pirkhaefi A. [The Effectiveness of clinical creativity therapy model on improving hope and happiness of the Patient with breast Cancer (Persian)]. Health Psychology. 2017; 6(21):52-65.

[20] Hertrampf RS, Wärja M. The effect of creative arts therapy and arts medicine on psychological outcomes in women with breast or gynecological cancer: A systematic review of artsbased interventions. The Arts in Psychotherapy. 2017; 56:93110. [DOI:10.1016/j.aip.2017.08.001]

[21] Faust-Socher A, Kenett YN, Cohen OS, Hassin-Baer S, Inzelberg R. Enhanced creative thinking under dopaminergic therapy in Parkinson disease. Annals of Neurology. 2014; 75(6):935-42. [DOI:10.1002/ana.24181] [PMID]

[22] Farmani F, Taghavi H, Fatemi A, Safavi S. The efficacy of group reality therapy on reducing stress, anxiety and depression in patients with Multiple Sclerosis (MS). International Journal of Applied Behavioral Sciences. 2015; 2(4):33-8. [DOI: 10.22037/ijabs.v2i4.11421]

[23] Sajjadi Monazah HR, Pirkhaefi A. [Effectiveness of creativity therapy model on improving motivation and students' educational performance (Persian)]. Quarterly Journal of Research in School and Virtual Learning. 2017; 4(4):39-48.

[24] McDonnell R. Creativity and mental health. In: McDonnell R, editor. Creativity and Social Support in Mental Health. London: Palgrave Macmillan; 2014. [DOI:10.1057/9781137345486_2]
[25] Yazdi-Ravandi S, Taslimi Z, Ahmadpanah M, Ghaleiha A Adjustment to diabetes among diabetic patients: the roles of social support and self-efficacy. Avicenna Journal of Neuro Psych Physiology. 2016; 3(1):1-7. [DOI:10.17795/ajnpp-37470]

[26] Glasser W. Choice Theory: A new psychology of personal freedom. New York: Harper Collins; 1999.

[27] Yazdi-Ravandi S, Taslimi ZA, Haghparast AB, Ghaleiha A. [Quality of life in patients with chronic pain disorders: determination the role of intensity and duration of pain (Persian)]. Koomesh. 2016; 17(4):836-43.

[28] Kanas N. The theory and practice of group psychotherapy. International Journal of Group Psychotherapy. 2011; 61(1):151. [DOI:10.1521/ijgp.2011.61.1.151]

[29] Shafieeabadi A, Gholamhossein-Ghashghaiee F. [Comparative effectiveness of group consultation of reality therapy and feminism on identity of women headed families (Persian)]. Women in Development and Policy. 2011; 9(4)93-113. 